\title{
Retinoblastoma pT2b TNM Finding v7
}

National Cancer Institute

\section{Source}

National Cancer Institute. Retinoblastoma pT2b TNM Finding v7. NCI Thesaurus. Code C88732.

Retinoblastoma with tumor superficially invading optic nerve head but not extending past lamina cribrosa and exhibiting focal choroidal invasion. (from AJCC 7th Ed.) 